\title{
Evaluasi Kinerja Lulusan Prodi D3 Kebidanan Undiksha Pada Fasilitas Rumah Sakit Pemerintah Se Bali
}

\author{
I Ketut Wijana* \\ Jurusan Analis Kesehatan Politeknik Kesehatan Kemenkes Denpasar, Bali
}

\author{
A R T I C L E I N F O \\ Article history: \\ Received 19 February 2018 \\ Received in revised form \\ 10 March 2018 \\ Accepted 12 April 2018 \\ Available online 25 May \\ 2018

\section{Kata Kunci:} \\ Evaluasi mutu, Studi Kinerja \\ para lulusan \\ Keywords: \\ Evaluation of the \\ Performance, graduates
}

\begin{abstract}
A B S T R A K
Penelitian ini bertujuan untuk menggambarkan mutu lulusan dengan melakukan evaluasi kinerja lulusan melalui penilaian kinerja oleh Atasan, Rekan kerja, Masyarakat penerima pelayanan dari lulusan dan juga pendapat dari lulusan sendiri. Penelitian ini bersifat "Ex Post Facto" dengan pendekatan "one Shot". Penelitian ini dilaksanakan pada fasilitas pemerintah yaitu Rumah Sakit dan Puskesmas dimana lulusan D3 kebidanan bertugas, yang melibatkan 472 responden dengan rincian; 100 responden dari atasan, 116 responden dari rekan kerja lulusan, masyarakat penerima pelayanan 140 responden, dan lulusan sendiri sebanyak 116 responden. Teknik sampling yang digunakan yaitu "total sampling" dengan melakukan penelusuran tempat-tempat lulusan bekerja. Data yang diproleh dianalisis dengan menggunakan metode deskriptif kuantitatif, hasil yang didapatkan adalah sebagai berikut: (1) Penilaian kinerja menurut atasan lulusan adalah cukup sebanyak $43 \%$, baik $24 \%$ kurang $22 \%$, sangat baik $8 \%$ dan sangat kurang $3 \%$. (2) Penilaian kinerja menurut rekan kerja lulusan cukup 48,38 \%, baik 23,27 $\%$, kurang $17 \%$, sangat baik 7,75\% dan sangat kurang 3,4\%. Hasil dari penelitian ini dijadikan bahan untuk mengintrospeksi kebijakan yang sudah ada untuk melakukan perbaikan agar lebih baik
\end{abstract}

A B S T R A C T

This study aimed at describing the quality of the graduates by conducting an evaluation of the performance of the graduates through the evaluation of their managers, colleagues, the people who have used their services and also the opinions of the graduates themselves. The study was an ex post facto study that used one shot approach. The study was conducted at Bali Province's health facilities or hospitals and community health centers where the graduates of the worked and involved 472 respondents: 100 health facility managers, 116 colleagues of the graduates, 140 people who used their services and 116 graduates themselves. The study used total sampling technique by conducting a tracing study at the graduates' workplaces. The data were analyzed by descriptive quantitative method and showed the following results: (1) according to the managers of the graduates, $43 \%$ of the graduates' performances fell into the category sufficient, $24 \%$ into the category good, $22 \%$ into the category insufficient, $8 \%$ into the category very good, and $3 \%$ into the category very insufficient.(2) according to the colleagues of the graduates, $48.38 \%$ of the graduates' performances fell into category sufficient, $23.27 \%$ into the category good, $17 \%$ into the category insufficient, $7.75 \%$ into the category very good and $3.4 \%$ into the category very insufficient.

\footnotetext{
* Corresponding author.

E-mail addresses: ketutwijana2204@gmail.com ( I Ketut Wijana)
} 


\section{Pendahuluan}

Sebagai institusi pendidikan yang mengelola prodi kebidanan sudah menjadi suatu kewajiban untuk memproduksi sumber daya manusia dalam bidang kebidanan yang berkualitas, ditandai dengan lulusan mampu menguasai teori, keterampilan kebidanan, beretika dan bertanggung jawab, pada era persaingan yang sedemikian ketat meningkatkan mutu lulusan sangatlah penting, hingga perlu dilakukan perubahan-perubahan sedemikian rupa agar kita selalu mampu memenuhi keinginan dari masyarakat sesuai dengan eranya, jika kita tidak mampu untuk menyesuaian dengan tuntutan kebutuhan dari masyarakat maka, kita akan ditinggal oleh stikhorder, yang maknanya kita akan menciptakan pengangguran-pengangguran intelek, dan ini sangatlah tidak baik bagi dunia pendidikan.

Kurikulum sebagai pedoman dalam proses pembalajaran sangatlah menentukan arah dan kualitas lulusan dari institusi pendidikan, sementara kita sudah 5 (lima) tahun kita tidak pernah melakukan revisi kuri kulum pendidikan, pertanyaannya adalah, apakah kurikulum tersebut masih mungkin atau relevan dengan kondusi pada saat ini untuk kita pertahankan?.

Memeperhatikan permasalahan tersebut maka saya tertarik untuk ingin mengetahui, gambaran kualitas dari lulusan dengan melakukan penelitian dari lulusan yang berjudul judul; evaluasi mutu lulusan Prodi D3 kebidanan undiksha lulusan dilaksanakan hanya pada tempat - tempat kerja lulusan yang berada wilayah kerja Pemerintahan Provinsi Bali kususnya di rumah sakit pemerintah dan Puskesmas.

Dari pelaksanaan kegiatan tersebut maka bermanfaat pokok yang dioperoleh adalah : (1) orangorang akan memahami dan termotivasi menuju sasaran dan tujuan organisasi, (2) aktivitas-aktivitas akan dievaluasi, disesuaikan dan diterapkan dalam satu kesatuan cara, (3) memperkecil kesalahan komunikasi di antara tingkat-tingkat dalam organisasi.

Jadi dalam hal ini kepala pendidikan sebagai pemimpin hendaknya mampu menciptakan dan memelihara iklim kerja yang kondusif untuk pelaksanaan proses pendidikan dan latihan disekolah yang bersangkutan. Kinerja setiap orang dipengaruhi oleh tiga faktor, yaitu kompetensi individu, dukungan organisasi dan dukungan manajemen (Sefrina, 2016).

1. Pendekatan Sistem Pada Manajemen.

Mengetahui, memahami, dan mengelola proses yang saling terkait sebagai suatu sistem akan dapat memberikan sumbangan pada efektivitas dan efesiensi organisasi dalam mencapai tujuannya. Manfaat pokok dari penerapan ini adalah (1) integrasi dan kesesuaian porses akan mencapai hasil yang diinginkan, (2) kemampuan memfokuskan usaha-usaha pada proses-proses kunci dan (3) memberika kepercayaan pada pihak yang berkepentingan terhadap konsistensi, efektifitas dan efisiensi organisasi. Jadi dengan pendekatan sistem yang diciptakan dan dijalankan dalam pengelolaan lembaga maka semua mekanisme kerja dikendalikan dengan suatu aturan manajemen dan personil yang melaksanakan tugas berpedoman pada sistem tersebut, bukan dengan kehendaknya sendiri.

2. Perbaikan Berlanjut.

Perbaikan berlanjut kinerja suatu organisasi secara menyeluruh harus menjadi perhatian utama semua pihak, mulai dari pimpinan tertinggi sampai pada semua staf di lapisan bawah hendaknya menjadi tujuan tetap organisasi. Perbaikan berlanjut didefinisikan sebagai suatu proses yang berfokus pada upaya terus menerus meningkatkan efektifitas dan efisiensi organisasi untuk memenuhi kebijkan dan tujuan dari organisasi tersebut. Perbaikan berlanjut ini memerlukan langkah-langkah konsolidasi yang progresif, menanggapi kebutuhan pelanggan, dan akan menjamin suatu evolusi dinamik dari sistem manajemen mutu. Jadi pada prinsipnya perbaikan secara terus menerus yang diakukan lembaga adalah sebagai pantauan untuk secepatnya mengetahui suatu kelemahan maupun perubahan yang terjadi baik di internal maupun eksternal, kemudian mencarikan jalan keluar untuk melakukan perbaikan sehingga diperoleh hasil yang baik.

Pendekatan Fakta dalam Pengambilan Keputusan ( Factual Approach to Decision Making).

Setiap pengambilan keputusan pada tingkatan apa pun harus dilakukan berdasarkan pada analisis data dan informasi yang obyektif. Keputusan yang efektif adalah keputusan yang berdasarkan pada analisis data dan informasi untuk menghilangkan akar penyebab masalah, sehingga masalah-masalah dapat terselesaikan dengan baik. Jadi keputusan yang diambil dengan dukungan informasi dan data yang akurat diyakini memiliki kekuatan hukum yang cukup, karena segala konsekuensi dari keputusan itu dikaji melalui fakta lapangan.

Untuk tercapainya apa yang menjadi harapan bagi suatu lembaga institusi pendidikan, maka program mutu atau upaya-upaya untuk meningkatkan mutu lembaga pendidikan merupakan hal yang sangat penting. Menurut Nana Syaodih Sukmadinata (2002:10) Untuk melaksanakan program mutu perlu ada beberapa dasar yang kuat:

a) Komitmen pada perubahan. Pemimpin yang ingin menerapkan program mutu, haru memiliki komitmen atau tekad untuk berubah, sebab peningkatan mutu intinya adalah melakukan perubahan ke arah yang 
lebih baik dan lebih berbobot. Perubahan biasanya menimbulkan rasa takut, akan tetapi jika kita mendasarinya dengan komitmen maka dapat menghilangkan rasa takut itu sendiri.

b) Pemahaman yang jelas tentang kondisi yang ada. Banyak kegagalan yang dialami dalam melaksanakan perubahankarena melakukan sesuatu sebelum sesuatu itu jelas.

c) Mempunyai misi yang jelas tentang masa depan. Perubahan yang akan dilakukan sebaiknya didasari dengan visi tentang perkembangan, tantangan, masalah, kebutuhan, dan pelung yang akan dihadapi di masa yang akan datang. Visi tersebut pada dasarny hanya dimiliki oleh seorang pemimpin atau inovator, tetapi kemudian ditularkan kepada orang-orang yang akan melakukan perubahan tersebut. Visi dapat menjadi pedoman yang akan membimbing tim dalam perjalanan pelaksanaan program mutu.

d) Punya rencana yang jelas. Mengacu kepada visi, maka tim menyusun rencana yang jelas. Rencana menjadi pegangan dalam proses pelaksanaan program mutu. Pelaksanaan program mutu dipengaruhi oleh faktor internal maupun faktor external. Faktor-faktor internal maupun external tersebut akan selalu berubah. Rencana harus selalu diupdated sesuai dengan perubahan-perubahan tersebut. Tak ada program mutu yang stagnan(berhenti), dan tidak ada program yang identik, karena program mutu selalu didasarkan dan disesuaikan dengan kondisi lingkungan. Program mutu merefleksikan lingkungan pendidikan dimanapun ia berada.

Membuat model visual dari sekolah yang menetapkan mutu total. Sekolah yang menerapkan mutu total di topang oleh lima pilar,yaitu: (1) berfokus pada pengguna, (2) keterlibatan secara total semua anggota, (3) melakukan pengukuran, (4) komitmen pada perubahan, serta (5) penyempurnaan yang terus-menerus, menurut Jerome S. Arcaco dalam Syaodih Sukmadinata dkk (1995:17). Pilar-pilar tersebut dibangun atas keyakinan dan nilai-nilai yang menjadi pegangan dalam pendidikan. Keyakinan dan nilainilai tersebut sejalan dengan visi dan misi pendidikan (sekolah), tujuan jangka panjang dan pendek serta kriteria keberhasilan yang kritis. Model visual dari Arcaro dapat dilihat pada gambar berikut berikut.

Delapan (8) standar pendidikan nasional (SPN) yaitu : Standar isi, standar proses, standar kompetensi lulusan, standar pendidik dan tenaga pendidikan, standar sarana dan prasarana, standar pengelolaan, standar pembiayaan dan standar penilaian pendidikan.

\section{Metode}

Pada bagian ini akan dijelaskan mengenai rencana penelitian, waktu dan tempat penelitian, populasi dan sampel, variabel penelitian dan definisi oprasional, konstelasi variabel, metode pengumpulan data dan jastifikasi serta metode analisa data.

Jenis penelitian ini adalah deskriptif yang berfungsi untuk mendiskripsikan atau menggambarkan terhadap obyek yang diteliti dengan pendekatan ex-post facto peneliti berhubungan dengan variabel yang telah terjadi dan peneliti tidak perlu memberikan perlakukan terhadap variabel yang diteliti ( Nursalam, 2003). Pada prinsipnya penelitian ini mempergunakan pendekatan evaluative. Secara epistemologis di dalam pengumpulan data menggunakan pendekatan obyektif dan subyektif, karena disamping berpedoman pada data yang telah tersedia dalam suatu dokumen yang telah tersusun, juga berdasarkan wawancara kepada subyek penelitian.

Penelitian dilakukan di wilayah Pekerja Pemerintahan provinsi Bali yang terdiri dari 9 (sembilan) Kabupaten dan 1 (satu) Kodya dan masing Kabupaten maupun Kodya memiliki fasilitas kesehatan rumah sakit milik pemerintah dan juga Puskesmas yang ada di kecamatan baik dengan fasilitas rawat jalan maupun dengan rawat nginap.

Populasi dalam penelitian ini adalah sebagai berikut, (1) lulusan Prodi D3 kebidanan Undiksha yang telah memiliki masa kerja minimal 1 (satu) tahun dan belum melanjutkan pendidikan ke jenjang yang lebih tinggi serta bertugas pada institusi kesehatan pemerintah se Provinsi Bali, seperti Rumah Sakit Pemerintah dan Puskesmas, (2) atasan adalah atasan langsung pada unit kerja dimana lulusan bertugas, (3) teman kerja dalam hal ini adalah rekan kerja dalam satu tim dimana lulusan bertugas.

Tehnik sampling yang digunakan dalam penelitian ini menggunakan 2 (dua) tehnik, yang pertama khusus dalam responden pengguna lulusan, atasan langsung, rekan kerja lulusan dan lulusan Prodi D3 Kebidanan sendiri menggunakan Snowball sampling, dimana peneliti terlebih dahulu mencari lulusan sendiri selanjutnya baru melanjutkan mencari sample terkait seperti atasan langsung lulusan sebanyak 100 responden, sampel untuk rekan kerja lulusan sebanyak 116 responden dan samepel dari lulusan sendiri yaitu sebanyak 116 responden.

Menghitung nilai dari masing-masing responden. 


$$
\mathrm{N}=\frac{\sum \text { nilaiObservasi }}{\sum \text { nilaildeal }} \times 100 \%
$$

Keterangan.

$\mathrm{N}=$ Nilai yang diperoleh responden.

Mencari nilai Mean dari data responden dengan rumus.

Mean $=\frac{\sum x}{n}$

Keterangan

$\mathrm{X}=$ Nilai dari Responden

$\mathrm{n}=$ Jumlah Responden

Tahap berikutnya mencari Standard Deviasi.

$$
S=\sqrt{\frac{\sum X_{i}^{2}-\frac{\left(\sum X_{i}\right)^{2}}{n}}{n-1}}
$$

Tahapan selanjutnya menentukan Kategori dari nilai masing-masing responden. Dalam hal ini peneliti membagi menjadi dalam 5 (lima) kategori yaitu sangat Baik, Baik, Cukup, Kurang dan Sangat Kurang, maka ketentuan parameter yang digunakan:

3.8.4.1 Sangat Baik, bila $x>$ Mean $+1,5$ SD.

3.8.4.2 Baik, bila Mean + 0,5 SD $<\mathrm{x}<$ Mean $+1,5 \mathrm{SD}$.

3.8.4.3 Cukup, bila Mean - 0,5 SD $<\mathrm{x}<$ Mean + 0,5 SD.

3.8.4.4 Kurang, bila Mean $-1,5 \mathrm{SD}<\mathrm{x}<$ Mean $-0,5 \mathrm{SD}$.

3.8.4.5 Kurang Sekali, bila $x<$ Mean - 1,5 SD.

Keterangan

$\mathrm{X}=$ Nilai yang diproleh dari Responden

\section{Hasil dan pembahasan}

Di dalam Bab IV ini peneliti akan menyajikan hasil dan pengelolaan data penelitian dalam bentuk profil sekolah, deskripsi data, analisa data dan temuan, pembahasan, simpulan, implikasi dan rekomendasi..

pengguna lulusan dalam hal ini atasan langsung lulusan bervariasi dari kategori sangat baik hingga ke sangat kurang, namun yang paling banyak adalah dengan kategori cukup yaitu berjumlah 43 orang $(43 \%)$ disusul oleh kategori baik yaitu sejumlah 24 orang $(24 \%)$ dan kategori kurang sebanyak 22 orang atau $22 \%$. Jumlah responden pada atasan sebanyak 100 orang responden dengan skor tertinggi yaitu $\leq$ 95,152 sebanyak 8 orang dan skor terendah $<$ 80,128 sebanyak 3 orang responden, penilaian kurang dan Sangat kurang dikarenakan rendahnya kesadaran dari lulusan untuk memberikan bimbingan kepada rekan kerja di samping itu juga akibat dari kualitas dan kuantítas hasil kerja masíh kurang hal ini dapat dilihat pada gambar 4.1. Sementara untuk nilai Mean $=87,64$ dan standar deviasi $=5,008 . \quad$ Gambar 4.1

Dari tabel 4.2. di atas menggambarkan bahwa penilaian yang diberikan oleh rekan kerja lulusan cukup bervariasi dari kategori sangat baik hingga ke sangat kurang, namun yang paling banyak adalah dengan kategori cukup yaitu berjumlah 56 orang (48,38\%) dengan interval nilai 89,375 s sampai dengan , 89,375 disusul oleh kategori baik yaitu sejumlah 27 orang $(23,27 \%)$ dan kategori kurang sebanyak 20 orang atau $17,2 \%$. Jumlah responden pada rekan kerja lulusan sejumlah 116 orang responden dengan skor tertinggi yaitu $\leq 95,747$ sebanyak 9 orang dan skor terendah $<76,631$ sebanyak 4 orang responden hal ini terjadi didorong oleh penilaian dari rekankerja lulusan yang menilai beberapa dari lulusan kemampuan dalam melakukan pemeriksaan laboratorium sebagai penunjang dalam menentukan diagnosis kurang untuk lebih jelasnya dapat dilihat pada gambar 4.2, sementara nilai Mean $=86,189$ dan standar deviasi $=6,372$.

Peran pendidikan sangat penting sebagai institusi yang memiliki tugas memproduksi dan membentuk manusia yang berkualitas termasuk didalamnya cerdas, damai, terbuka dan demokratis, oleh karena itu prubahan-perubahan menuju perbaikan sebagai usaha untuk meningkatkan mutu pendidikan harus selalu dilakukan guna tersedianya lulusan sebagai tenaga kerja yang betul-betul siap untuk bekerja dan bersaing baik pada tataran lokal, nasional maupun internasional. Untuk meningkatkan mutu pendidikan pemerintah harus lebih banyak berperan terutama dalam menentukan kebijakan pendidikan 
dengan memberikan kebebasan setiap pengelola pendidikan untuk mengembangkan pendidikan sesuai dengan kebutuhan, tuntutan perkembangan jaman, paling tidak pemerintah harus selalu membuat standar, menentukan kreteria, pengawasan melakukan evaluasi dan pembinaan secara pariodik terhadap institusi pendidikan yang ada, sehingga pendidikan yang ada betul-betul mampu memproduksi tenaga yang berkualitas mampu berkompetitif dan dapat memenuhi kebutuhan tuntutan konsumen sesuai dengan prasyarat yang di inginkan oleh konsumen. Prodi D3 Kebidanan merupakan pendidikan tinggi yang secara khusus memproduksi atau menamatkan tenaga-tenaga terampil, terlatih dan siap untuk dipekerjakan, mudah beradaptasi dengan lingkungan dan perubahan serta dapat mengembangkan diri dalam rangka memenuhi pasar kerja diberbagai institusi kesehatan yang selalu berkembang, dan mampu bersaing dikancah lokal, nasional maupun internasional.

Mengantisipasi tantangan dan tututan untuk memenuhi persyaratan pasar kerja baik nasional maupun internasional, pihak pendidikan harus selalu melakukan perbaikan-perbaikan yang inovatif sesuai dengan tuntutan secara periodik baik pada input maupun proses pendidikan dan juga secara bertahap pengelola pendidikan selalu berusaha untuk melengkapi seluruh fasilitas pendidikan dan juga senantiasa meningkatkan pendidikan staf pengajar dengan memprogramkan setiap tahun mengirim staf pengajar untuk melanjutkan pendidikan kejenjang yang lebih tinggi disamping juga meng ikutsertakan staf Tata Usaha dan Pengajar dalam setiap pelatihan yang ada dan sesuai dengan kebutuhan pendidikan.

Penelitian ini dilaksanakan dengan menggunakan model penelusuran para lulusan (treasure study) di tempat - tempat mereka bertugas kususnya pada pelayanan - pelayanan kesehatan milik pemerintah. Yang melibatkan sebanyak 472 responden dengan rincian atasan lulusan sebanyak 100 orang, rekan kerja lulusan 116 orang, masyarakat pengguna pelayanan dari lulusan sebanyak 140 orang dan lulusan sendiri sebanyak 116 orang. Untuk mendapatkan informasi yang dibutuhkan pada penelitian ini menggunakan kuisioner dengan mengadopsi model skala Likert yaitu sangat baik, baik, cukup, kurang dan sangat kurang informasi didapatkan langsung data primer dari informasi atau pendapat yang diberikan oleh responden. Data yang telah diolah atau diproses pada penelitian ini selanjutnya diberikan skor, selanjutnya untuk mengkategorikan skor yang diproleh dari masing-masing responden dibuat penjenjangan kategori yang didahului dengan mencari nilai mean dari masing - masing kelompok responden selanjutnya mencari nilai Standar Deviasi dan diteruskan pembuatan jenjang interval dari masing-masing kategori tersebut.

Dari hasil penelitian menujukkan bahwa : (1) pendapat atau penilaian yang diberikan terhadap lulusan oleh atasannya adalah kebanyakan dengan kategori cukup yaitu berjumlah $43 \%$ dan kategori baik sebanyak $24 \%$, (2) sementara penilaian yang diberikan oleh rekan kerja lulusan yaitu 48,38 \% dengan kategori cukup dan 23,27 \%,

\section{Simpulan dan saran}

Berdasarkan hasil penelitian tentang analisis kadar nitrit dalam produk daging olahan yang beredar di wilayah Denpasar, dapat diperoleh beberapa simpulan sebagai berikut: 1) Semua sampel uji (18 buah) yang dianalisis mengandung nitrit dengan kadar yang bervariasi yaitu antara 27,392 - 231,362 mg/kg, 2) Kandungan nitrit terendah ditemukan dalam sampel A1 dengan kadar sebesar 27,392 mg/kg dan terbesar dalam sampel F1 dengan kadar sebesar 231,362 mg/kg, dan 3) Terdapat 6 sampel sosis yang mengandung nitrit diatas baku mutu yang telah diatur melalui Permenkes R.I. No. 1168/Menkes/Per/1999 yaitu sampel sampel F1, J1, M1, N1, 01 dan R1.

Berdasarkan hasil penelitian, dapat diberikan beberapa saran sebagai berikut: 1) Instansi terkait diharapkan dapat melakukan sosialisasi mengenai peraturan tentang penggunaan BTP dan bahayanya bagi kesehatan serta edukasi bagi konsumen, terutama tentang bahan pengawet nitrit dalam daging olahan, 2) Instansi terkait diharapkan dapat melakukan monitoring secara berkala terhadap kandungan BTP dalam bahan pangan, terutama nitrit pada produk daging olahan yang telah beredar secara luas di masyarakat, dan 3) Perlu dilakukan analisis kadar nitrit dalam produk daging olahan lain dan produk pangan lain serta analisis kandungan nitrit dalam air minum.

\section{Daftar Rujukan}

Adi Utama. Pedoman Dasar Pelaksanaan Jaminan Mutu di Rumah Sakit. Jakarta: Depkes RI. 2003

Andreas Lako. Kepemimpinan dan Kinerja Organisasi. Yogjakarta: Penerbit Amara Books. 2004.

Dirjen Binkesmas RI. Kompetensi Bidan Indonesia. Jakarta: Ikatan Bidan Indonesia. 2000

Dirjen Binkesmas. Pedoman Dasar Pelaksanaan Jaminan Mutu di Puskesmas . Jakarta: Depkes RI. 2003

Dirjen Binkesmas. Kebijakan dasar pusat kesehatan masyarakat. Jakarta : Depkes RI. 2004 
Dirjen Dikti. Praktek Baik Dalam Penjaminan Mutu Pendidikan Tinggi. Jakarta Diknas RI. 2005

Farida Yusuf Tayibnapis. Evaluasi Program. Jakarta. PT.Rineka Cipta. 2000

Gaspersz. Metode Audisi untuk Peningkatan Kualitas. Jakarta: PT. Gramedia Pustaka Utama. 2003

Istiyanto. Riset Sumber Daya Manusia. Jakarta : PT. Gramedia Pustaka Utama. 2007

Karting Kartono. Pemimpin dan Kepemimpinan. Jakarta: PT. Raja Grafida Persada. 2004

Koyan I Wayan. Buku Ajar Statistika Terapan. Singaraja : Program Pasca Sarjana Undiksha. 2007

Menkes RI. Panduan Bidan di Tingkat Desa. Jakarta. Depkes RI. 2004

Nana Syaodih Sukmadinata,dkk . Pengendalian Mutu Pendidikan. Bandung: Kusuma Karya. 2002

Nursalam. Konsep dan penerapan Metodelogi Penelitian Ilmu Keperawatan. Jakarta: Salemba medika. 2003

Patricia Buhler. Management skills in 24 Hours. Jakarta: Prenada Media. 2004

POGI. Buku Acuan Nasional Program Menjaga Mutu Pelayanan Kesehatan. Jakarta: JNPKK-POGI. 2006

Pusdiknakes RI. Pedoman penjamin mutu pendidikan tenaga kesehatan. Jakarta : Depkes RI. 2008

Riwidigdo Handoko. Statistik Kesehatan. Jogjakarta: Mitra Cendikia. 2008

Sedarmayanti. Sumber Daya Manusia dan Produktivitas Kerja. 2001

Sefrina, Yosi. 2016. Kinerja Lulusan Diploma Iii Kebidanan Politeknik Kesehatan Kementerian Kesehatan Padang Menurut Pengguna Lulusan. Jurnal Medika Saintika Vol 7 (1).

Sondang P. Siagian. Kiat Meningkatkan Produktifitas Kerja. Jakarta: Penerbit Rineka Cipta. 2002

Suharsini Arikunto. Evaluasi Program Pendidikan. Jakarta: PT. Bumi Aksara. 2004

Sudarwan Danim. Visi Baru Manajemen Sekolah. Jakarta: PT. Bumi Aksara. 2006

Sugiyono. Statistika Untuk Penelitian. Bandung: Alfabeta. 2006

Sumiatun. 2013. Analisis Mutu Pembelajaran Praktikum Kebidanan Sebagai Upaya Peningkatan Pencapaian Kompetensi Program Studi Diploma III Kebidanan STIKES Maharani Malang. Jurnal Kebijakan dan Pengembangan Pendidikan Volume 1, Nomor 1.

Supriyanto. S. Manajemen Mutu. Surabaya: Universitas Airlangga. 2007 